\title{
An Empirical Study on the Factor Structure of Organization
}

\author{
Yang Jingzhao \\ College of Business Administration \\ Jiangsu University \\ Zhenjiang, China \\ yangjz@ujs.edu.cn
}

\author{
Ma Hongqi \\ College of Business Administration \\ Jiangsu University \\ Zhenjiang,China \\ mahongqi0535@126.com
}

\author{
Zhu Jiajia \\ College of Business Administration \\ Jiangsu University \\ Zhenjiang, China
}

\begin{abstract}
In view of the importance of organizational structure and the current situation of lack of documentation which discuss the measurement of organizational structure, this paper has verified that three factors-complexity, normalization and centralization can be used to measure organizational structure, which is based on data analysis collected in an empirical study. The questionnaire is designed by comprehensive analysis of the three dimensionalities of organization and the relevant literature. Through the course of the study, we handed out questionnaires written in Chinese to 256 companies and we got 208 companies' reply with a usability rate of $81.25 \%$. Then this paper verifies the three factors model from the perspective of reliability and validity respectively. Finally, The test results show that the reliability and validity of the questionnaire are high and we can regard organizational structure as a three factors model.
\end{abstract}

Keywords-organizational structure; reliability analysis; validity analysis

\section{INTRODUCTION}

As an organizational environment factor, organizational structure means that organizational framework represents the way of allocation for resources in internal organizational which includes human, financial, material resources and its structure stability of arrangement[1]. Robbins divides organize structure into functional, division form, simple form, matrix form and network form, task group form and committee form from three dimensions: the leading policy value goals selection, legitimacy, and their validity. Similarly, Zhang Gang divides organizational structure into four classes: pure level structure, functional structure, decentralized structure and right variant organization[2]. In the 1980s, the enterprise organizational structure began to convert into decentralized structure, but this structure is still with hierarchy. The goal for right variant organization is to coordinate technology development activities effectively, and successful enterprises tend to apply this organizational structure in the 1990s. The references are limited for the way to estimate organizational structure. This paper will do some research for measurement of organizational structure based on the three basic nature of organization.

\section{THE DEVELOPMENT AND RECENSION OF SCALE}

On the basis of a large number of references, the author designed neither questionnaire. During the design process of questionnaire, the author followed the following principles:
First, the problems in the questionnaire should be concise, easy to answer and attractive. Using closed question and ensuring quality of the answers, we will use Likert's 5 point scoring form, in order to answer the question expediently, be convenient to organize and analysis data. Secondly, the inquiry and optional answer of the questionnaire should prevent tendentiousness happening to keep the objectivity and fairness.

According to Robbins, organizational structure has threedimensional characteristics:complexity, the degree of regularization and the level of centralization. On this basis, the author designed ten items graded by Likert's type scale to distinguish the degree of normality and centralization. Through internal personnel subjective evaluation and the scale's objective evaluation, we can make a relatively impartial judgment for the organizational structure [3], as shown in table I.

TABLE I. THE SCALE OF ORGANIZATIONAL STRUCTURE

1. The numbers of employees

2. The condition of administrative organization's setup

3. Strict hierarchy

4. Decision-making process highly concentrated; question bottomup reflection

5. The responsibilities of each post are fixed;

6. Perfect regulations and procedures to guide employees' behavior

7. Communicate through formal channels

8. Many transverse cooperation relationship

9. More attention paid to exerting its whole advantage

10. More attention paid to each department's performance

The respondents to the survey are responsible persons such as general manager, deputy general managers and human resource manager, etc. They are suitable to be the key respondents because they know related structure well. The size of sample sizes should be as larger as possible, then the estimator will more precise and the statements will be more persuasive[4,5]. According to the above principles, we handed out the questionnaire written in Chinese to 256 companies. Finally, we got 208 companies' reply with a usability rate of $81.25 \%$. After sorting out the invalid questionnaires, there were 143 valid questionnaires, and we withdrew 204 valid questionnaires. The basic statistic analysis of organizational samples is as shown in table II. 
TABLE II. THE DESCRIPTIVE STATISTICAL ANALYSIS OF VARIABLES

\begin{tabular}{lccccc}
\hline Variable & Sample & $\begin{array}{l}\text { Mean } \\
\text { value }\end{array}$ & $\begin{array}{l}\text { Standard } \\
\text { error }\end{array}$ & $\begin{array}{l}\text { Least } \\
\text { value }\end{array}$ & $\begin{array}{l}\text { Maximum } \\
\text { value }\end{array}$ \\
\hline $\begin{array}{l}\text { Years of } \\
\text { firms }\end{array}$ & 204 & 13.58 & 10.19 & 2.00 & 57.00 \\
$\begin{array}{l}\text { Number of } \\
\text { employees }\end{array}$ & 204 & 740.57 & 3276.37 & 1.00 & 33396.00 \\
$\begin{array}{l}\text { Number of } \\
\text { employees } \\
\text { with colle- }\end{array}$ & 204 & 38.83 & 24.15 & 3.00 & 100.00 \\
ge gradua- \\
te degree
\end{tabular}

\section{EXPLORATORY FACTOR ANALYSIS OF THE SCALE}

Questionnaire is designed after analyzing the three dimensionalities of organization and consulting the relevant literature. So, EFA is very necessary for our scale. First, we used 100 samples to have an EFA, while the rest of the samples would use to have a confirmatory factor analysis [6]. The prerequisite of exploratory factor analysis is that there should be strong relevance between different measurement items. Therefore, the researchers had Kaiser-Meyer-Olkin and Bartlett's Test in advance. Generally, if the measured value of KMO being greater than 0.9 , it is very suitable for factor analysis; if the measured value being in between 0.7 0.9 , it fits to do factor analysis; if the measured value being in between $0.5-0.7$, it suits to do factor analysis; while the measured value being less than 0.5 , it is not suitable for factor analysis. Finally, we proved that the result is 0.683 by calculating and it is suitable to do factor analysis. The measured value of Bartlett 's Test is less than $1 \%$ of the given the significant level, which means the original variables suit to do factor analysis.

This paper adopted Varimax Method, namely we used Orthogonal Rotation to analysis each measurement indexes and finally we got three factors. The value of each items' load is as shown in table III.

TABLE III. THE FACTOR LOAD VALUE AFTER MAXIMUM VARIANCE ROTATED

\begin{tabular}{|c|c|c|c|}
\hline & \multicolumn{3}{|c|}{ Factor } \\
\hline Item & $\mathbf{1}$ & $\mathbf{2}$ & $\mathbf{3}$ \\
\hline Item 1 & .023 & -.020 & .820 \\
Item 2 & -.104 & .104 & .744 \\
Item 3 & -.042 & .710 & .085 \\
Item 4 & .274 & .660 & .189 \\
Item 5 & .070 & .722 & -.265 \\
Item 6 & .439 & .486 & .233 \\
Item 7 & .585 & .263 & -.284 \\
Item 8 & .669 & .069 & -.014 \\
Item 9 & .766 & -.139 & .074 \\
Item 10 & .601 & .318 & -.099 \\
\hline
\end{tabular}

Generally, it is significant if the absolute value of factor's load is greater than 0.3 . The greater the absolute value of factor's load is, the more important it would be in explaining factor. If the value of the load is just 0.3 , then the parts of the factors explained will be less than $10 \%$. According to this principle, the standard of load can be set as the value greater than 0.5 . The value of each factor's load is as shown in table IV.

TABLE IV. THE FACTOR ANALYSIS TABLES OF ORGANIZATIONAL STRUCTURE

\begin{tabular}{|c|r|r|r|}
\cline { 2 - 4 } Item & Factor 1 & Factor 2 & Factor 3 \\
\hline Item 1 & & & .805 \\
Item 2 & & .721 \\
Item 3 & & .610 & \\
Item 4 & & .722 & \\
Item 5 & & .486 & \\
Item 6 & & & \\
Item 7 & .585 & & \\
Item 8 & .669 & & \\
Item 9 & .766 & & \\
Item 10 & .601 & & \\
\hline
\end{tabular}

Based on above theoretical analysis, the three factors are named complexity, the degree of regularization and the degree of centralization respectively[7,8]. The dimensions of organizational structure are shown in table $\mathrm{V}$.

TABLE V. THE DIMENSION REPARTITION TABLE OF ORGANIZATIONAL STRUCTURE

\begin{tabular}{|c|c|}
\hline \multirow{2}{*}{ Complexity } & 1.The numbers of employees \\
\hline & 2.The condition of administrative organization's setup \\
\hline \multirow{4}{*}{ Centralization } & 3.Strict hierarchy \\
\hline & $\begin{array}{l}\text { 4.Decision-making process highly concentrated; question } \\
\text { bottom-up reflection }\end{array}$ \\
\hline & 5.The responsibilities of each post are fixed; \\
\hline & $\begin{array}{l}\text { 6.Have perfect regulations and procedures to guide } \\
\text { employees' behaviour }\end{array}$ \\
\hline \multirow{4}{*}{ Normalization } & 7.Communicate through formal channels \\
\hline & 8.Many transverse cooperation relationship \\
\hline & 9.More attention paid to exerting its whole advantage \\
\hline & 10.More attention paid to each department's performance \\
\hline
\end{tabular}

The explained variance of each factor is shown in tableVI.

TABLE VI. THE QUANTITY EXPLAINED BY TOTAL VARIANCE

\begin{tabular}{|c|c|c|}
\hline Factor & Quantity explained \% & Summation \% \\
\hline 1 & 21.185 & 21.185 \\
2 & 19.012 & 40.197 \\
3 & 15.031 & 55.228 \\
\hline
\end{tabular}

According to the result of our analysis, the value of each factor's load is greater than 0.5 , and the total value of factors' load is $55.228 \%$. It is suitable to use the three factors to analyze structure of organization because the empirical results accord with the requirements of each index and have strong theoretical support. The three factors graph of organizational structure is shown in figure 1. 


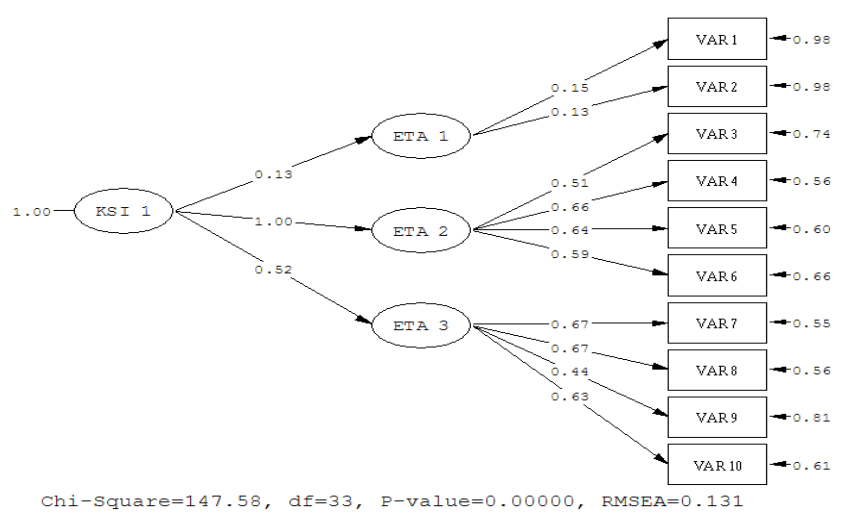

Figure 1. The three factors graph of organizational structure.

\section{Reliability ANALYSIS OF THE SCALE}

This paper adopts Cronbach's Alpha to measure the reliability of the scale, which is the more commonly used value in measuring reliability in sociological research. The larger the value of $\alpha$ is, the higher the reliability of scale is. In this article, if the value of Cronbach 's Alpha is less than 0.35 , the value can be deemed with low reliability and we refuse to accept it. However, if it exceeds 0.5 , it is acceptable.

The measurement of reliability of the scale is shown in table.

TABLE VII. THE RELIABILITY ANALYSIS OF THE SCALE

\begin{tabular}{|c|c|c|}
\hline Architecture & Number of terms & Cronbach's Alpha \\
\hline Organizational structure & 10 & 0.596 \\
\hline Normalization & 4 & 0.623 \\
\hline Centralization & 4 & 0.632 \\
\hline Complexity & 2 & 0.654 \\
\hline
\end{tabular}

The value of Cronbach's Alpha of the three dimensions of organizational structure all exceeds 0.5 , so it is acceptable.

\section{VALIDITY ANALYSIS OF THE SCALE}

This paper used lisrel8.7 software package and Structural Equation Modeling to make a confirmatory factor analysis. Structural Equation Modeling (SEM) belongs to confirmatory means, rather than exploratory methods. Therefore, in allusion to one model, we can use it to analyse the empirical data.

According to the results of confirmatory factors' analysis, the parameter's estimate of the three factors model is shown in table VIII.

TABLE VIII. THE PARAMETER ESTIMATION TABLE OF THREE FACTORS HYPOTHESIS MEASUREMENT MODEL

\begin{tabular}{|c|c|c|c|c|}
\hline Parameter & $\begin{array}{l}\text { Nonstandar- } \\
\text { d parameter } \\
\text { values }\end{array}$ & $\begin{array}{c}\text { Standard } \\
\text { error }\end{array}$ & $\begin{array}{l}\text { The } \\
\text { value } \\
\text { of } T\end{array}$ & $\begin{array}{c}\text { Standardization } \\
\text { parameters }\end{array}$ \\
\hline Item 1 & 1.13 & 0.29 & 3.96 & 0.75 \\
\hline Item 2 & 0.75 & 0.19 & 3.88 & 0.66 \\
\hline Item 3 & 0.36 & 0.07 & 4.82 & 0.39 \\
\hline
\end{tabular}

\begin{tabular}{|c|c|c|c|c|}
\hline Item 4 & 0.59 & 0.07 & 8.62 & 0.68 \\
\hline Item 5 & 0.42 & 0.07 & 6.14 & 0.49 \\
\hline Item 6 & 0.44 & 0.05 & 8.06 & 0.64 \\
\hline Item 7 & 0.36 & 0.05 & 7.02 & 0.57 \\
\hline Item 8 & 0.33 & 0.05 & 6.72 & 0.54 \\
\hline Item 9 & 0.30 & 0.05 & 5.76 & 0.47 \\
\hline Item 10 & 0.50 & 0.06 & 7.68 & 0.62 \\
\hline
\end{tabular}

The absolute value of standardized parameters is in between 0.39-0.75 can be seen from the table, not greater than 1 , which mean that the value of the parameters is appropriate. Secondly, the measuring error in between 0.05 0.19 , not too big and without negative error, these results suggest that there are no phenomenon of violation of estimates. Therefore, we can evaluate the whole model. The results of confirmatory factors' analysis of each latent variable are shown in table IX.

All indexes in above scale are used to measure the degree of fitting between model and the data. The meaning of each index is as follows (Huang Fangming.2006):

The chi-square $(\chi 2 / \mathrm{df})$ shows that the degree of difference between the matrix educed by SEM and the view matrix. If the value of $\chi 2 / \mathrm{df}$ is less than 3 , it means the value is acceptable. The value in this article is 2.45 , which show the whole model is fitting very well.

Comparative - Fit Index (CFI) shows that the degree of difference between hypothetical models and the independent model without any change together relations, which should be larger than 0.9 . The value in this paper is 0.92 , so the degree of difference between three factors model and independent organizational architecture models is obvious.

Root Mean Square Error of Approximation (RMSEA) shows that the degree of difference between the theory and the above model. The smaller the value is, the higher the degree of fitting is. Generally the value recommend is equal or less than 0.05 , and the value in this paper is 0.064 less than 0.08 , so we can accept it.

Goodness-of-Fit Index (GFI) shows the variance ratio of the observed variables. Generally the value recommend is larger than 0.9 , and the value in this paper is 0.95 , so we can accept it.

The Adjusted GFI (AGFI) shows the explicable variation, with the same criteria to GFI. Generally the value recommend is larger than 0.9 , and the value in this paper is 0.91 , so we can accept it.

\section{ACKNOWLEDGMENT}

In summary, the test results show that the reliability and validity of the questionnaire are high and we can regard organizational structure as a three factors model.

\section{REFERENCES}

[1] Stephen P. Robbins,Management, 4rd ed.,vol.12. Beijing: China Renmin University Press,1996, pp.252-263.

[2] Zhang Gang and Xu Qingrui," "Cultural Type,Organizational Structure And Enterprise Technological Innovation," Science Research Management, vol. 5, 1996, pp. 26-32.

[3] D.S.Pugh, D.J.Hickson, C.R.Hinings, and C.Turner, "Dimensions of organizational structures,"Administrative Science Quarterly, vol.13, Jun.1968,pp.65-105. 
[4] Hair, J. E., Anderson, R. E., Tatham, R. L.,and Black,W. C., Multivariate data analysis with readings. 5rd ed.,Englewood Cliffs, NJ:Prentice-Hall International Editions, 1998

[5] He Xiaoqun, "The statistical principle of Six Sigma," China Statistics,vol. 12, 2004,pp.44-46.

[6] Guo Zhigang. Social statistical analysis method. Beijing: China Renmin University Press, 2006.
[7] Alfred Chandler. Strategy and Structure. Kunming: Yunnan Renmin Press. 2002.

[8] LinYuanbo,DuGuang,and Lu Jia,"Structure complexity measurement and complex structure organization,"Journal of Beijing Institute of Technology(Social Sciences Edition),vol.11,2009,pp.20-23.

TABLE IX. THE MAINLY ADAPTIVE INDEX OF ORGANIZATIONAL STRUCTURE

\begin{tabular}{|c|c|c|c|c|c|c|c|c|}
\hline Latent variable & Factor contained & $\boldsymbol{\chi 2}$ & $\mathbf{d f}$ & $\boldsymbol{\chi 2}$ /df & $\mathbf{C F I}$ & $\mathbf{R M S E A}$ & GFI & AGFI \\
\hline Organizational structure & 3 & 80.36 & 33 & 2.45 & 0.92 & 0.064 & 0.95 & 0.91 \\
\hline
\end{tabular}

